\title{
A INTERPRETAÇÃO DE J. L. BORGES SOBRE A METÁFORA NO TEXTO FILOSÓFICO
}

\section{The J. L. Borges's interpretation about the metaphor in the philosophical text}

Daniel Omar Perez ${ }^{1}$

\section{Resumo}

Este artigo tem como objetivo mostrar que a escrita borgeseana é um trabalho de desarticulação da metafísica que opera, em um dos seus modos, pela análise da metáfora. Para isso, primeiro, mostraremos a relação literatura - filosofia em Borges, em segundo lugar, reconstruiremos alguns dos trabalhos de Borges sobre a metáfora no texto filosófico, procurando buscar pontos de contato com a leitura heideggeriana. Finalmente mediremos seu alcance.

Palavras-chave: Borges; Heidegger; Literatura; Filosofia.

\section{Abstract}

This paper aims to show that Borges's writing is a work of disjoint of the metaphisics wich operates, in one of tis ways, through the analysis of the metaphor. For this, firstly, we'll show the relationship literaturephilosophy in Borges, Secondly, we'll rebuild some of Borges's pieces of work about the metaphor in the philosophical text searching for contact points with the heideggerian reading. Finally we'll measure its length of reach.

Keywords: Borges; Heidegger; Metaphor; Literature; Philosophy.

1 Doutor em Filosofia pela Unicamp, Professor de Filosofia do Programa de Pós-graduação em Filosofia da Pontifícia Universidade Católica do Paraná (Curitiba). Presidente da Seção Campinas (Unicamp) da Sociedade Kant Brasileira. Pontifícia Universidade Católica do Paraná, Centro de Teologia e Ciências Humanas, Departamento de Filosofia. Rua Imaculada Conceição, 1155 CEP 80215-901 - Curitiba, PR - Brasil. Telefone: (41) 3271-2626 Ramal: 2230

E-mail : danielomarperez@hotmail.com

Revista de Filosofia, Curitiba, v. 16 n.19, p. 11-26, jul./dez. 2004. 


\section{Borges e Filosofia}

Seria dúbia a tarefa que procurasse demarcar na obra de Jorge Luis Borges a jurisdição específica na qual sua escrita perpassa os problemas da filosofia. A referência à tradição metafísica exibe os nomes de Hume, Heráclito, Platão, Schopenhauer, Nietzsche ou ainda Swedenborg, Ângelus Silesius, Boecio e Meister Eckart entre outros. Mas não diríamos nada se apenas afirmássemos que nessa linhagem reside uma espécie de vocação especulativa ou um simples jogo da curiosidade literária. Há uma preocupação ainda maior em Borges que exige determinadas tomadas de posição com respeito à escrita filosófica. Os escritos dos comentadores sobre este aspecto abrangem quase todo o leque de filiações possíveis. Jaime Rest, por exemplo, decide que Borges pertence ao nominalismo da filosofia analítica anglosaxõa ${ }^{2}$. Ana Maria Barrenechea sugere o panteísmo nilista para explicar a linha de pensamento de Borges ${ }^{3}$. Já o crítico Jaime Alazraki pensa que 0 spinozismo expressa bem a reflexão do nosso escritor ${ }^{2}$. Entretanto, Juan Nuño postula o platonismo ${ }^{4}$. A lista de variedades pode continuar mostrando múltiplas leituras e recortes do texto borgeseano. Nos colóquios de Leipzig (1999) e Veneça, organizados por Alfonso de Toro ${ }^{5}$, Borges foi associado à figura de Derrida, Vatimo, Foucault, Rorty, Eco, etc.

Mas, esta variabilidade interpretativa não é apenas patrimônio dos comentadores. O próprio Borges também tinha várias versões da sua relação com a filosofia. Geralmente se apresentava nas entrevistas como um cético. Em diálogo com Maria Esther Vazquez, em 1973, Borges fez a seguinte declaração:

Yo no tengo ninguna teoría del mundo. En general, como yo he usado los diversos sistemas metafísicos y teológicos para fines literarios los lectores han creído que yo profesaba esos sistemas, cuando realmente

1 BARRENECHEA, Ana Maria: La expresión de la irrealidad en la obra de Borges. Buenos Aires: Piados, 1967.

2 ALAZRAKI, Jaime: La prosa narrativa de Jorge Luis Borges. Madrid: Gredos, 1968.

3 NUÑO, JuaN: La filosofia de Borges. México: FCE, 1986.

4 DE TORO, Alfonso \& DE TORO, Fernando (Org.): El siglo de Borges. Vol.I. Retrospectiva Presente - Futuro. Madrid: Iberoamericana, 1999. DE TORO, Alfonso \& REGAZZONI, Susana (Org.): El siglo de Borges. Vol. II. Literatura - Ciencia - Filosofia. Madrid: Iberoamericana, 1999.

5 VÁZQUEZ, Maria Esther: Borges. Imágenes, memoria, diálogos. Carácas: Monte Ávila, 1977. 
lo único que he hecho ha sido aprovecharlos para esos fines, nada mas. Además, si yo tuviera que definirme, me definiría como un agnóstico, es decir, una persona que no cree que el conocimiento sea posible" ${ }^{\prime \prime}$.

Seu agnosticismo se manifesta em uma espécie de teoria da leitura, um exercício textual que põe em funcionamento quando cruza literatura com filosofia.

Por outro lado, nas Notas do livro Discusión (1932), referindo-se à filosofia, Borges escreve:

Yo he compilado alguna vez uma antologia de la literatura fantástica. Admito que esa obra es de las poquísimas que un segundo Noe debería salvar de un segundo diluvio, pero delato la culpable omisión de los insospechadosy mayores maestros del género: Parménides, Platón, Juan Escoto de Erígena, Alberto Magno, Spinoza, Leibniz, Kant, Francis Bradley. En efecto, que son los prodigios de Wells o de Edgar Allan Poe una flor que nos llega del porvenir, un muerto sometido a la hipnosisconfrontados con la invención de Dios, con la teoría laboriosa de un ser que de algún modo es tres y que solitariamente perdura fuera del tiempo? Que es la piedra beozar ante la armonía preestablecida, quien es el unicornio ante la trinidad, quien es Lucio Apuleyo ante los multiplicadores de Budas del Gran Vehículo, que son todas las noches de Sharazad junto a un argumento de Berkeley?

Esta declaração parece ir ao encontro de outro escrito borgeseano de Ficciones (1944), onde Borges diz que em Tlön, Uqbar, Orbis Tertius a metafísica é um tipo de literatura fantástica ${ }^{8}$, como também de alguns ensaios redigidos em El livro de arena (1975).

Assim, o Borges do ceticismo passa para o Borges dos escritos de ficção. Mas entre um e outro aparece uma figura que permite pensar mais cabalmente a sua relação com a filosofia. Em vários momentos ele se definiu como um argentino perdido na metafísica ${ }^{9}$. Talvez essa afir-

BORGES, Jorge Luis: Obras Completas.Vol. I. BsAs: Emece, 1989, p. 280-1.

Op.Cit. p. 437.

8 Op.Cit. "Nueva refutación del tiempo" O.C. Vol. II, p. 135.

9 Esta estratégia de Borges é mencionada por RITVO, Juan Bautista: "El filósofo sublime", in Revista Sitio, nro. 4/5 Rosario-Arg. Mayo de 1985; e em GIORDANO, Alberto: "El ensayista argentino y la tradición", in Borges y Bioy Casares ensayistas, Rosario: Ediciones Paradoxa, 1988.

Revista de Filosofia, Curitiba, v. 16 n.19, p. 11-26, jul./ dez. 2004. 
mação deva ser entendida como sugere Juan Jacinto Muñoz Rengel que diz que o extravio é a própria metafísica. A hipótese de uma metafísica como extravio, explorada por Borges, pode nos fazer pensar no fio condutor de uma aparente multiplicidade de versões da relação Borges/Filosofia. Assim como Kant utilizou a metáfora do mar sem orla para se referir à metafísica, que segundo ele formulava problemas sem sentido, podemos pensar o caráter ficcional da metafísica que propicia as condições de seu próprio extravio. Assim, Borges se extravia na multiplicidade de relatos de uma metafísica como gênero da literatura fantástica e ressurge desse extravio no exercício de sua escrita. A pergunta então é: Como se realiza essa concepção ficcional da filosofia no exercício da escrita literária ou ensaística borgeseana? Colocando de manifesto o caráter ficcional da filosofia. Trata-se de um trabalho de desarticulação dos argumentos e dos princípios utilizados na montagem das teorias filosóficas com o intuito de mostrar sua artificialidade. Este trabalho de Borges tem várias entradas. Uma delas, talvez a mais importante (e tentaremos dar provas disso) é a análise das metáforas. Borges desarticula os textos filosóficos em vários momentos mostrando sua instância última como metafórica. Essa é a via da escrita que utilizou, por exemplo, na Historia de la Eternidad (1936), onde 0 tratamento dos argumentos filosóficos chega a passar da ironia ao humor. Borges lê os conceitos da metafísica como metáforas ${ }^{10}$. Neste sentido, não podemos esquecer a análise feita sobre as teorias nietzscheanas do eterno retorno em La doctrina de los ciclos e de Platão sobre o tempo, como também não podemos deixar de lembrar o texto sobre a esfera de Pascal.

\section{A leitura borgeseana de Nietzsche}

No escrito sobre Nietzsche, Borges procura levantar várias questões para se contrapor à doutrina nietzscheana do eterno retorno do mesmo, mostrando a fraqueza dos argumentos do filósofo pelo absurdo. Para sustentar sua tese, Nietzsche afirma que o total da força no universo é finito e determinado e o tempo, onde o todo exerce sua força, é infinito. Portanto, é de admitir que esta mesma situação, entanto combinação de forças finitas em um tempo infinito, já aconteceu inúmeras vezes. Por

10 NIETZSCHE, Friederich: Obras incompletas. São Paulo: Editora Nova Cultural, 1999, p. 440.

Revista de Filosofia, Curitiba, v. 16 n.19, p. 11-26, jul./dez. 2004. 
um cálculo, poderíamos demonstrar que o que está acontecendo agora já aconteceu e acontecerá. Não se trata de uma passagem perdida ou uma frase solta entre os papéis do filósofo. Trata-se de uma reflexão meditada em vários momentos da obra e reforçada com uma série de argumentos. Os elementos de origem são mensurados devidamente: força, tempo, combinatória. O cálculo cosmológico é ensaiado de diversos modos: Que nada retorne não poderia ser explicado pelo acaso, mas somente por uma intencionalidade posta na essência da força.. ${ }^{11}$. E é claro que Nietzsche não quer acrescentar qualquer coisa à simplicidade da essência da força. Muito menos ainda uma intencionalidade que implicaria em um entendimento divino. Para Nietzsche, a força é essencialmente simples e, por isso, mensurável na sua escassez tanto de quantidade quanto de possibilidades. Na tentativa de dar provas convincentes de sua teoria cosmológica, Nietzsche opõe sua concepção do processo circular do todo às concepções teistas. Mostra também que é mais verossímil um mesmo lance de dados se repetir que a absoluta nunca igualdade. Fala do orgânico, das tendências, do equilíbrio, do caos, da diminuição e do aumento, quer dizer, toca em quase todos os estados de um sistema cosmológico para defender sua tese. E finalmente escreve:

Assim este instante: ele já esteve aí uma vez e muitas vezes e igualmente retornará, todas as forças repartidas exatamente como agora: e do mesmo modo se passa com o instante que gerou este, e com o que é filho do de agora. Homem! Tua vida inteira, como uma ampulheta, será sempre desvirada outra vez e sempre se escoará outra vez -, um grande minuto de tempo no intervalo, até que todas as condições, a partir das quais vieste a ser, se reúnam outra vez no curso circular do mundo. E então encontrarás cada dor e cada prazer e cada amigo e inimigo e cada esperança e cada erro e cada folha de grama e cada raio de sol outra vez, a inteira conexão de todas as cosas. Esse anel em que és um grão, resplandece sempre outra vez. ${ }^{12}$

Deste modo, fica estabelecida quase que tragicamente a finitude do Universo. Para polemizar com esta doutrina, Borges começa fazendo os cálculos do número de mudanças possíveis em um Universo de dez átomos e a cifra é 3.628.800.

11 Op. Cit, p. 442.

12 BORGES, Jorge Luis: Obras Completas. Vol. I. BsAs: Emece, 1989, p. 385.

Revista de Filosofia, Curitiba, v. 16 n.19, p. 11-26, jul./ dez. 2004. 
Si una partícula casi infinitesimal de universo es capaz de esa variedad -escreve Borges- poca o ninguna fe debemos prestar a una monotonía del cosmos. He considerado diez átomos; para obtener dos gramos de hidrógeno precisaría mos bastante mas de un billón de billones. Hacer el cómputo de los cambios posibles en ese par de gramos - vale decir, multiplicar un billón de billones por cada uno de los números enteros que lo anteceden- es ya una operación muy superior a mi paciencia humana ${ }^{13}$.

É claro que esta operação ainda não refuta a tese nietzscheana da finitude do Universo, mas Borges parece buscar relativizá-la. Mostrando números inintuíveis para a compreensão humana, Borges parece buscar abalar seu efeito de verossimilhança. Quer dizer, o fato do lance de dados se repetir não é tão verossímil assim. Antes mesmo de saber se a tese é verdadeira ou falsa, Borges pretende derrubar o brilho e a contundência retórica que poderia ter a teoria do filósofo do martelo.

No passo seguinte, Borges apela para a teoria de conjuntos de Cantor e mostra que se aceitarmos sua tese (a de Cantor), podemos dizer que a quantidade de pontos que há no universo é a mesma que há em um decímetro. E ainda, se pudermos intercalar sempre mais um ponto entre dois pontos dados, então o número de pontos (no Universo ou em um decímetro) é infinito. Com a teoria de Cantor no papel, Borges mostra que a questão da simplicidade da força ou é uma decisão metafísica ou é uma questão numérica, sendo numérica então é indeterminada e assim a teoria cosmológica de Nietzsche não se sustentaria. Por outro lado, se for uma decisão metafísica, então o filósofo deveria dar argumentos para poder "decidir" porque essa decisão é melhor do que as outras, de Platão a Hegel.

Outra estratégia utilizada por Borges se baseia na segunda lei da termodinâmica. A projeção de luz numa superfície negra transforma esta em calor. A química não se deixa reduzir a um cálculo funcional ou à comutação de elementos. Assim como este, qualquer ou tro processo de irreversibilidade, como um simples papel queimando, anularia "o labirinto circular do eterno retorno"14.

Mas se pensarmos que não se trata de cosmologia e sim de ética, que aquilo que Nietzsche está reivindicando é homens capazes de suportar as coisas tal qual são, mesmo assim, a questão que Borges quer mos-

${ }^{13}$ BORGES, Jorge Luis: Obras Completas. Vol. I. BsAs: Emece, 1989, p. 391. ${ }^{14}$ BORGES, Jorge Luis: Obras Completas. Vol. I. BsAs: Emece, 1989, p. 369.

Revista de Filosofia, Curitiba, v. 16 n.19, p. 11-26, jul./dez. 2004. 
trar não muda. O escritor traça um paralelo entre um parágrafo escrito por Nietzsche em 1883 e outros que falam sobre os pita gôricos e os estóicos mostrando que a idéia da repetição dos atos humanos e das coisas se repete numa história de repetições. Mas isso não é importante, o copyrigth é uma questão de direito e do que aqui se trata é de questões de fato. Do fato da repetição dos atos e das coisas como metáfora, Nietzsche buscaria um efeito ético. Viver de tal modo que quiséramos voltar a viver, e assim por toda a eternidade. Com efeito, escreve Borges:

Nietzsche quería ser Walt Whitman, quería minusiosamente enamorarse de su destino. Siguió um método heróico: desenterro la intolerable hipótesis griega de la eterna repetición y procuró deducir de esa pesadilla mental una ocasión de júbilo. Buscó la idea más horrible del universo y la propuso a la delectación de los hombres ${ }^{15}$.

Trata-se de uma metáfora horrível, sem dúvidas. $\mathrm{O}$ eterno retorno seria uma metáfora, mas metáfora de quê? Na mesma época, talvez nas mesmas tardes em que Borges pensava no sentido do eterno retorno do mesmo, Heidegger escrevia seu Nietzsche apontando para o mesmo conceito, mas ele fazia isso em alemão. Deixemos momentaneamente aberta a pergunta e vamos a outro caso.

\section{A leitura borgeseana de Platão}

Borges aborda a leitura de Platão por uma das definições mais antigas da metafísica, e talvez a que contém todas as outras. Trata-se da caracterização do tempo como a imagem móbil da eternidade. Borges comenta a noção de eternidade surgida da teoria dos arquétipos, avalia seus argumentos no que eles têm de virtuosos e deficientes. Em um segundo momento, passa para a análise da noção cristã. A eternidade é pen sada a partir da Trindade. Borges aplica o mesmo procedimento que no exercício anterior e revela sua inconcebivilidade. Falar da eternidade para explicar o tempo se descobre como um procedimento não menos árduo que o de definir o tempo pura e simplesmente. "La eternidad escreve Borges - es una copiosa invención. Es decir que no es concebi-

15 BORGES, Jorge Luis: Obras Completas. Vol. I. BsAs: Emece, 1989, p. 365.

Revista de Filosofia, Curitiba, v. 16 n.19, p. 11-26, jul./dez. 2004. 
ble, pero el humilde tiempo sucesivo tampoco lo es"16. A figura da imagem móbil da eternidade revela-se como metáfora. Mas metáfora de algo inconcebível, inexplicável, algo que não pode ser dito, senão apenas na sua instância metafórica. Assim, podemos perguntar com Santo Agostinho: $\mathrm{O}$ que é o Tempo? Se não perguntarem eu sei, se perguntarem eu não posso dizer.

Uma interpretação crítica análoga encontramos em Martin Heidegger, em O conceito de tempo (1924), onde escreve que:

se o tempo encontrar seu sentido na eternidade, então deve ser compreendido a partir dela. Com isso ficam determinados o ponto de partida e o caminho desta pesquisa: da eternidade para o tempo. Este questionamento está em ordem pressuposto que dispomos do ponto de partida enunciado eque, portanto, conhecemos a eternidade e a compreendemos suficientemente ${ }^{17}$.

Borges e Heidegger descobrem a eternidade como um início inadequado ou impossível para entender o tempo. A eternidade se apresenta como uma ficção e seus argumentos como um relato da literatura fantástica. As analogias traçadas entre Heidegger e Borges neste ponto não terminam por aí. Quando Borges pensa a "origem" da noção de eternidade recorre a uma espécie de fenomenologia do ânimo. Ele escreve:

Pienso que la nostalgia fue ese modelo. El hombre enternecido y desterrado que rememora posibilidades felices, las vé sub specie aeternitas, con olvido total de que la ejecución de una de ellas excluye o posterga las otras. En la pasión, el recuerdo se inclina a lo intemporal. Congregamos las dichas de un pasado, en una sola imagen; los ponientes inmensamente rojos que miro cada tarde, serán en el recuerdo un solo poniente. Con la previsión pasa igual: las mas incompatibles esperanzas pueden convivir sin estorbo. Dicho sea con otras palabras: el estilo del deseo es la eternidad ${ }^{17}$.

\footnotetext{
16 HEIDEGGER, Martin: "O conceito de tempo". In cadernos de tradução - USP, p. 7, 1997.

17 BORGES, Jorge Luis: Obras Completas. Vol. I. BsAs: Emece, 1989, p. 365.
} 
A eternidade é a metáfora dos momentos felizes projetados no futuro. Estas linhas vão ao encontro da reflexão heideggeriana que declararia que a eternidade éuma estra tégia da metafísica para esquecer a morte. Da mesma morte que Borges nos lembra em Sentirse em muerte, publicado em El idioma de los argentinos (1928), em que escreve que a idéia de eternidade poderia surgir do fato da vida ser bastante pobre para não ser imortal. Assim, inventamos uma ficção metafísica, que aparece na figura de uma metáfora, para poder suportar nossa finitude. Seria fácil achar outros paralelos, por exemplo, em El tiempo (1978), em que Borges escreve que "la totalidad del ser es imposible para nosotros. Así nos dan todo, pero gradualmente". Dito em termos heideggerianos, 0 ser dá-se no tempo. Mas o que interessa aqui não é tanto a semelhança com Heidegger quanto a operação de desarticulação da metafísica do escrito borgeseano pelo desvelamento da metáfora.

\section{A leitura borgeseana de Pascal}

No escrito de 1951, intitulado La esfera de Pascal, Jorge Luis Borges procura mostrar que todo o percurso da história do pensamento ocidental pode ser apresentado como uma história composta por umas poucas metáforas. Ele transita por alguns textos buscando explicitar a questão pela metáfora da esfera eterna. É com Xenófanes de Colofón, século VI a.C., que Borges inicia sua reflexão sobre a metáfora do Deus único a partir do pensamento da esfera. Xenófanes foi aquele que fustigó a los poetas que atribuían carácter antropomórfico a los dioses, propondo um só Deus. Através do Timeu de Platão é que Xenófanes obteve a caracterização da esfera como la figura mas perfecta y mas uniforme, porque todos los puntos de su superficie equidistan del centro. Assim, ele teria representado a unidade absoluta pelas características da esfera, ou seja, de um Deus esferóide. Em outro escrito antigo, o de Parmênides, é declarado que el ser es semejante a la masa de una esfera bien redonda, cuya fuerza es constante desde el centro en cualquier dirección. Segundo os comenta dores Calogero e Mondolfo (historiadores da filosofia ocidental) - comenta Borges -, Parmênides intuyó una esfera infinita o infinitamente creciente concedendo um sentido dinâmico a essa esfera inaudita. Também na cosmogonia de Empédocles encontramos que las partículas de tierra, de água, de aire y de fuego integran una esfera sin

Revista de Filosofia, Curitiba, v. 16 n.19, p. 11-26, jul./dez. 2004. 
fin, o Sphairos redondo. Nos livros herméticos desde o Corpus Hermeticum até o teólogo Alain de Lille encontramos que: Dios es una esfera ininteligible, cuyo centro está em todas partes y su circunferencia en ninguna. Para os medievais, o sentido dessa figura era evidente: Deus está em cada uma das suas criaturas, porém nenhuma o limita. Posteriormente, Giordano Bruno inferiu, em defesa do mundo copernicano, que: podemos afirmar com certeza que el universo es todo centro, o que el centro Del universo está em todas partes y su circunferencia en ninguna. Essa colocação ocorre em defesa do questionamento sobre a necessidade do sistema ptoloméico que é composto por esferas concên tricas. Entretanto, para Pascal também existe: una esfera espantosa, cuyo centro está en todas partes y su circunferencia en ninguna.

O pensamento da esfera apresenta todos os requisitos da metáfora. Por um lado, a estrutura sintagmática aparece autocontraditória: seu centro está em todas as partes e sua circunferência em nenhuma. Por outro lado, seu sentido deve ser pensado como remitido a um outro significado que aquele de uma esfera estranha ou espantosa, cujo centro está em todas as partes e sua circunferência em nenhuma. Neste caso, é a própria estrutura formal que nos autoriza a pensar em um sentido não literal do conceito. Por um lado, o pensamento da esfera apresentaria a possibilidade de sentido da estrutura que quer ser explicada, por outro lado, indicaria para aquilo que já não mais deve ser apresentado. $\mathrm{O}$ pensamento da esfera é metafórico não porque relembre um segundo sentido, mas porque indica para a própria possibilidade de sentido, possibilidade esta que não pode ser dita senão através do esquecimento na imagem metafísica, de um pensamento negativo nas formas da teologia ou tal vez da poesia, escrita metafórica por excelência.

Outra das metáforas, que Borges não cita, e que poderia apresentar a história do pensamento ocidental é a do estado de Natureza que sustenta totalmente o pensamento político da modernidade e sem a qual não existiria idéia de contrato.

\section{O esquecimento como metáfora}

Se concedermos o argumento de que a filosofia deve pensar o sentido, então devemos concordar com que o esforço empreendido pela metafísica para responder a pergunta pelo sentido originou um trajeto

Revista de Filosofia, Curitiba, v. 16 n.19, p. 11-26, jul./dez. 2004. 
histórico que pode ser definido junto com Heidegger como história do esquecimento do ser. O caminho inicial que trilhou a metafísica mostrou-se dominante em todo o curso dos textos filosóficos e depende do sentido concedido, fundamentalmente, pela filosofia platônica e aristotélica ${ }^{18}$. A história da metafísica se caracteriza, portanto, por uma determinada compreensão de ser que o interpreta a partir da totalidade do ente. Escreve Heidegger: o Uno enquanto unidade unificante servirá de norma para a determinação posterior do $\operatorname{ser}^{19}$. A metafísica realizou seu percurso histórico colocando estrategicamente o ente no lugar do ser. Desse modo, para dizer muito rapidamente e sem rodeios, na tradição, o ser foi pensado dentro das características e con dições próprias do ente, procurando apreende-lo através do pensamento da representação. A necessidade objetivante e presentificadora do pensamento humano acabou por encobrir a pergunta fundamental da filosofia, e isso ficou expresso na utilização de uma determinada imagem em cada caso.

O procedimento da metafísica consiste em escolher um en te dentre todos os entes e colocá-lo como Ser ou fundamento. Com isso, antes que o ser pudesse acon tecer de um modo próprio em sua verdade inicial, ele se encontra vinculado a imagens ônticas.

Na metafísica moderna o ente interpretado como fundamento passa a ser o homem na medida em que esse ente é estabelecido como sujeito. O esquecimento na época moderna acontece na medida em que o domínio representativo do sujeito e do objeto se consolida. Através do sujeito tudo passa a se converter em objeto. Nesse momen to da história do esquecimento do ser o en te é pen sado a partir da subjetividade do sujeito. A resposta de Descartes à interrogação da questão do ser fica a cargo do eu, sujeito pensante. Quando o filósofo estabelece o homem como sujeito pensante, o eu se transforma em todo o que é. O sujeito é consolidado como o fundamento de toda verdade. Tudo deve poder ser representado perante o eu. Para o eu cartesiano as coisas se apresentam na representação e podem ser apreendidas na medida em que são convertidas em objeto para o sujeito. $\mathrm{O}$ sujeito está no lugar do ser instalando o que é. $\mathrm{O}$ sujeito se transforma em pano de fundo, na base, no último ponto a ser pensado. A operação metafísica detém o pensamento nessa figura.

18 Ver HEIDEGGER, Martin: Ser e tempo. Petrópolis: Editora Vozes, 1999, §1.

19 Ver HEIDEGGER, Martin: Nietzsche. Vol. II.

Revista de Filosofia, Curitiba, v. 16 n.19, p. 11-26, jul./dez. 2004. 
No caso do trajeto filosófico de Nietzsche apresenta-se uma rejeição à metafísica e à concepção da filosofia fundada na tradição que pretende acabar com os seus fundamentos. O escritor Nietzsche questiona sobretudo a concepção da vida tal como foi compreendida até então pelo homem. Essa crítica reagiu de maneira penetrante contra o platonismo e a doutrina religiosa do cristianismo (o platonismo para o povo), como sendo ambos os principais respon sáveis pela compreensão errônea da filosofia ocidental. Nietzsche propõe, a partir daí, uma inversão de tudo o que se considerou como bom e verdadeiro. Essas questões deveriam ser problematizadas porque todas elas foram encobertas pelo valor e pela transcendência. A vida do homem éapresentada em função de uma determinada concepção de valor e de avaliações morais. O homem ocidental possui a necessidade de representação e de valoração para que possa compreender a vida. Essa compreen são se dá através de um sentido transcendente. Para Nietzsche, o sentido estaria dado pela metafísica a partir de um além, uma transcendência. A metafísica seria um encaminhamento para um "mundo verdadeiro" situado para além do mundo real, como degradado. Desde o início a metafísica colocou o problema da concepção da vida (aquilo que existe, o mundo, o ser no seu conjunto, etc.) como a questão do existente autêntico que sempre foi mostrando como a medida de toda determinação da condição do ser. Segundo a afirmação nietzscheana, no platonismo esse ser autêntico se encontra para além do mundo. Assim, existiria em Platão, por um lado, um mundo ultramundano de coisas eternas e, por outro lado, as coisas terrestres e finitas mostra das como meras cópias. O que Nietzsche percebe no platonismo é que existe uma operação de fundamentação hierárquica entre essas duas dimensões anteriormente citadas. Assim, a concepção platônica de vida e de mundo pressupõe uma outra dimensão, o mundo inteligível ou metafísico. Para que as coisas possuam um sentido deve haver um transcendente. A realidade do mundo deve pressupor o mundo inteligível. Desde Platão, toda a cultura ocidental estaria baseada na consideração de uma figura, de um conceito de verdade, de bondade, de ser, que nos permite medir e por sua vez fundamentar aquilo que existe no mundo. Esta figura aparece como a condição do existir mesmo das coisas. A esta "figura" Platão deu-lhe o nome de eidos. As idéias conferem forma a toda a existência das coisas perecíveis e limitadas. Desse modo, em todo o curso metafísico da tradição, algo deve ser colocado como o real para que a coisa possa ser. As dimensões do inteligível e do sensível 
passam a caracterizar horizontes diferentes em que somente o mundo transcendental pode pensar o ser do ente, ou melhor, onde somente este pode outorgar sentido aos entes intramundanos. Assim, para caracterizar as coisas deve-se pressupor sempre que há algo que não muda, que não é passível de transformação. Para Nietzsche a superação da metafísica baseia-se em uma crítica à transcen dên cia. Não existiria um fundamento do aquém no além e, portanto, não se poderia pensar a partir de uma essência. O que existe para o filósofo é a vontade de poder que em cada caso é. Através dos conceitos nietzscheanos de força e vontade de poder a transcendência deixaria de existir e o que agora se mostraria seria a pura imanência do ser.

Entretanto, segundo Heidegger, a inversão nietzscheana do platonismo permanece no interior da metafísica. Escreve Heidegger:

essa espécie de superação da metafísica, que Nietzsche tem em vista e, bem no sentido do positivismo do século XIX, não obstante numa transformação mais elevada, não passa de um envolvimen to definitivo com a metafísica. Parece na verdade que aqui se marginaliza o "meta, a transcendência rumo ao supra-sensível em favor de uma firme permanência no elementar da sensibilidade. Enquanto isso, porém, não se faz outra coisa do que dar acabamento ao esquecimento do ser, liberando e ocupando o supra-sensível como vontade de poder ${ }^{20}$.

Com efeito, para Heidegger, o problema em questão da metafísica não é apenas a relação de fundamentação hierárquica entendida em Nietzsche como crítica à transcendência, mas pensar o ser como presença, fixar o pensamento do ser em uma imagem, mesmo sensível. Assim, a vontade de poder se ergue como a causa primeira ou como a imagem primaria. A verdade do ente é mostrada através da vontade de poder e do eterno retorno. Esses dois conceitos expressam a maneira como Nietzsche compreende o ser do ente no seu conjunto. Para Heidegger, é justamente através da vontade de poder e do eterno retorno que Nietzsche acaba por pensar os fios condutores de toda a problemática metafísica, a essência e a existência. Vontade de poder e eterno retorno se colocam como figuras substitutivas do ser como presença, isto é, do esquecimento. Mesmo quando o eterno retorno já não funcione como

20 Ver HEIDEGGER, Martin: Ensaios e conferências. Petrópolis: Editora Vozes, 2002, p. 69.

Revista de Filosofia, Curitiba, v. 16 n.19, p. 11-26, jul./ dez. 2004. 
princípio ontológico senão como o apelo para de uma vida ética o sintagma re-envia para um outro sentido que o torna possível em seu esquecimento.

Mas o esquecimento é apenas um dos lados de uma dupla operação. É através da própria história do esquecimento do ser, impressa nas figuras da metafísica, que se torna possível investigar aquilo para onde se aponta. As figuras da metafísica, na mesma medida em que ocultam o sentido originário do ser o revelam. $\mathrm{O}$ que está em jogo é a dupla operação da figura metafísica que no mesmo momento em que oculta o sentido o revela na sua história. É devido à ocultação que se pode revelar e somente pode revelar-se como aquilo que é, ocultando-se nas figuras da metafísica. Se o processo da história da metafísica fosse apenas unívoco, isto é, de esquecimento, o pensamento do ser se colocaria como o coroamento de um tempo linear e unidirecional. Mas porque não é apenas esquecimento senão também revelação aquilo que se inscreve na metafísica é, então, que podemos pensar os sentidos do ser. Em uma dimensão a figura oculta, em outra revela. É a dinâmica própria da metáfora.

A metáfora é um tipo de metassemema. A definição geral de metassemema é a substituição de um significante por outro que comporta uma modificação do conteúdo semântico de um termo, essa modificação resulta da supressão e adição de semas. Formalmente a metáfora se liga, por um lado, a um sintagma onde aparecem contraditoriamente a identidade de dois significantes e, por outro lado, a não identidade de dos significados.

Nos casos das imagens metafísicas que apresentamos anteriormente, vemos funcionando dois níveis semânticos diversos. Um dentro da estrutura do próprio discurso (que remete a um tipo de significado e funciona como esquecimento) e o outro, na dimensão da história do ser (que remete a outro significado e funciona como revelação daquilo que é). A imagem metafísica se apresenta como fixando um sentido determinado à estrutura da presença, mas também como apresentando a possibilidade de sentido daquilo que não pode ser presente. A imagem metafísica é metáfora porque revela aquilo que oculta, e só pode funcionar desse modo.

Revista de Filosofia, Curitiba, v. 16 n.19, p. 11-26, jul./dez. 2004. 
Conclusões

Para finalizar, podemos dizer então que através de Borges, é possível dar conta da operação fundamental da metafísica como operação de metaforização, que no mesmo momento que funda e fecha um sentido na sua apresentação abre e enuncia a possibilidade daquilo que não pode ser apresentado de modo literal, e que só pode ser lembrado através do esquecimento, em algum sentido heideggeriano. Tal como escreve Borges, "é o esquecimento aquilo que permite a leitura".

\section{Referências}

ALAZRAKI, Jaime. La prosa narrativa de Jorge Luis Borges. Madrid: Gredos, 1968.

BARRENECHEA,Ana Maria. La expresión de la irrealidad en la obra de Borges. Buenos Aires: Piados, 1967.

BORGES, Jorge Luis. Obras Completas. Vol. I,II,III,IV. BsAs: Emece, 1989. DE TORO, Alfonso \& DE TORO, Fernando (Org.). El siglo de Borges. Vol.I. Retrospectiva - Presente - Futuro. Madrid: Iberoamenicana, 1999.

DE TORO, Alfonso \& REGAZZONI, Susana (Org.). El siglo de Borges. Vol. II. Literatura - Ciencia - Filosofia. Madrid: Iberoamericana, 1999.

GIORDANO, Alberto. El ensayista argentino y la tradición. In: Borges y Bioy Casares ensayistas. Rosário: Paradoxa, 1988.

HEIDEGGER, Martin. O conceito de tempo. In: Cadernos de tradução. USP, 1997.

SEGUIDOS DE PONTO FINAL

Ser e tempo. Petrópolis: Vozes, 1999. 6 TOQUES

Ensaios e conferências. Petrópolis: Vozes, 2002.

IDEM

NIETZSCHE, Friederich. Obras incompletas. São Paulo: Nova Cultural, 1999.

Revista de Filosofia, Curitiba, v. 16 n.19, p. 11-26, jul./dez. 2004. 
NUÑO, JuaN. La filosofia de Borges. México: FCE, 1986.

REST, Jaime. El laberinto del universo. Borges y el pensamiento nominalista. Buenos Aires: Fausto, 1976.

RITVO, Juan Bautista. El filósofo sublime. Revista Sitio, nro. 4/5 Rosario-Arg. Mayo de 1985. LOCAL, N. MES E ANO.

VÁZQUEZ, Maria Esther. Borges. Imágenes, memoria, diálogos. Carácas: Monte Ávila, 1977.

Recebido em - Recieved in: 22/07/2004 Aprovado em - Approved in: 12/08/2004 